\title{
DOSES, FONTES E ÉPOCAS DE APLICAÇÃO DE NITROGÊNIO INFLUENCIANDO TEORES DE CLOROFILA E PRODUTIVIDADE DO TRIGO ${ }^{(1)}$
}

\author{
Eduardo Quimello Theago ${ }^{(2)}$, Salatiér Buzetti ${ }^{(3)}$, Marcelo Carvalho Minhoto Teixeira \\ Filho $^{(4)}$, Marcelo Andreotti ${ }^{(5)}$, Marcio Mahmoud Megda ${ }^{(6)}$ \& Cleiton Gredson Sabin \\ Benett $^{(7)}$
}

RESUMO

\begin{abstract}
Para obter altas produtividades de trigo, são necessários o manejo correto da adubação nitrogenada e a utilização de cultivares de alto potencial produtivo. Sendo assim, objetivou-se avaliar doses e fontes de nitrogênio $(\mathrm{N})$, aplicadas totalmente em semeadura ou em cobertura, na produção e nos seus componentes em dois cultivares de trigo irrigado, em sistema de plantio direto, cultivado numa região de cerrado de baixa altitude. $O$ delineamento experimental foi em blocos ao acaso, em esquema fatorial $5 \times 3 \times 2 \times 2$, com três repetições, combinando cinco doses de $\mathbf{N}(0$, $50,100,150$ e $200 \mathrm{~kg} \mathrm{ha}^{-1}$ ), três fontes de N (Entec ${ }^{\circledR}$, sulfato de amônio e ureia), duas épocas de aplicação de $\mathrm{N}$ (na semeadura, ao lado das linhas, ou em cobertura), e em dois cultivares de trigo (IAC 370 e Embrapa 21). Os cultivares de trigo tiveram produtividade de grãos semelhantes. As fontes de $\mathrm{N}$ não diferiram para produtividade de grãos e demais avaliações. $\mathrm{O}$ N fornecido totalmente na semeadura não diferiu da aplicação tradicional, em semeadura e cobertura, para a produção do trigo irrigado em plantio direto. $\mathrm{O}$ incremento das doses de $\mathrm{N}$ aumentou os teores foliares de $\mathrm{N}$ e de clorofila, a altura de plantas e o número de espigas por $\mathbf{m}^{2}$. A produtividade de grãos dos cultivares IAC 370 e Embrapa 21 aumentaram até as doses de 134 e $128 \mathrm{~kg} \mathrm{ha}^{-1}$ de $\mathrm{N}$, respectivamente, independentemente da época de aplicação e da fonte de $\mathrm{N}$. A correlação positiva entre o teor de clorofila e a produtividade de grãos em razão das doses de $\mathrm{N}$ indicou que a adubação nitrogenada
\end{abstract}

(1) Recebido para publicação em 16 de setembro de 2013 e aprovado em 28 de julho de 2014.

(2) Engenheiro Agrônomo, Faculdade de Engenharia, Universidade Estadual Paulista - UNESP, Campus de Ilha Solteira. Caixa Postal 31. CEP 15385-000 Ilha Solteira (SP). Bolsista PIBIC/CNPq. E-mail: du_theago@hotmail.com

(3) Professor Titular, Departamento de Fitossanidade, Engenharia Rural e Solo - DFERS, UNESP, Campus de Ilha Solteira. Bolsista em produtividade pelo CNPq. E-mail: sbuzetti@agr.feis.unesp.br

(4) Professor Assistente, UNESP, Campus de Ilha Solteira. E-mail: mcmteixeirafilho@agr.feis.unesp.br

(5) Professor Adjunto, DFERS, UNESP, Campus de Ilha Solteira. E-mail: dreotti@agr.feis.unesp.br

(6) Pós-doutorando, DFERS, UNESP, Campus de Ilha Solteira. E-mail: marcio_agr@yahoo.com.br

(7) Pós-doutorando, Escola de Agronomia, Universidade Federal de Goiás. Rod. GO-330, km 241, Anel Viário s/n. CEP $75780-000$ Ipameri (GO). E-mail: cbenett@hotmail.com 


\begin{abstract}
de cobertura pode ser recomendada a partir das leituras (SPAD) de clorofila realizadas aos 38 dias, após a emergência do trigo.
\end{abstract}

Termos de indexação: Triticum aestivum L., adubação nitrogenada, Cerrado, cereais de inverno, plantio direto.

\title{
SUMMARY: NITROGEN APPLICATION RATES, SOURCES, AND TIMES AFFECTING CHLOROPHYLL CONTENT AND WHEAT YIELD
}

\begin{abstract}
To achieve high wheat yield, correct management of $N$ fertilization and the use of high yield potential cultivars are necessary. The aim of this study was to evaluate the effects of different application rates and sources of $N$, applied totally at sowing or in topdressing, on grain yield and yield components of two irrigated wheat cultivars under a no-till system, grown in a Cerrado (Brazilian tropical savanna) region of low altitude. A randomized block design was used in a $5 \times 3 \times 2 \times 2$ factorial arrangement with three replications, combining five levels of $N\left(0,50,100,150\right.$, and $\left.200 \mathrm{~kg} \mathrm{ha}^{-1}\right)$, three sources of $N$ (Entec ${ }^{\circ}$, ammonium sulfate, and urea), and two application times (at sowing, near the rows, or in topdressing) in two wheat cultivars (IAC 370 and Embrapa 21). The wheat cultivars had similar grain yields. There was no difference among the sources of $N$ for grain yield and yield components. The $N$ applied totally at sowing did not differ from the traditional application at sowing and in topdressing for production of irrigated wheat in no-tillage. The increase in application rates of $N$ increased the leaf $N$ contents and chlorophyll, plant height, and the number of ears per $\mathrm{m}^{2}$. Grain yield of the wheat cultivars IAC 370 and Embrapa 21 increased up to the application rates of 134 and $128 \mathrm{~kg} \mathrm{ha}^{-1}$ of $N$, respectively, regardless of application time and source of $N$. The positive correlation between chlorophyll leaf content and grain yield in accordance with $N$ fertilization levels indicates that $N$ fertilization in topdressing can be recommended based on $S P A D$ readings of leaf chlorophyll performed at 38 days after wheat plant emergence.

Index terms: Triticum aestivum L., nitrogen fertilization, Cerrado, no-tillage, winter cereal crops.
\end{abstract}

\section{INTRODUÇÃO}

$\mathrm{O}$ nitrogênio $(\mathrm{N})$ é o nutriente mais difícil de ser manejado nos solos de regiões tropicais e subtropicais, em virtude do grande número de reações a que está sujeito e da sua alta instabilidade no solo (Ernani, 2003). No trigo, pequenas doses limitam a produtividade e altas doses podem levar ao acamamento, dificultando a colheita e resultando em queda de produtividade, além de contaminar o ambiente, em razão da lixiviação de nitrato para o lençol freático e do prejuízo para o produtor. Portanto, a adubação nitrogenada requer cuidados em seu manuseio tanto no que concerne às doses aplicadas quanto à época de aplicação.

Um dos aspectos mais polêmicos no manejo da adubação nitrogenada de gramíneas, no sistema plantio direto (SPD) com sucessão de gramíneas, é a época de aplicação de $\mathrm{N}$, uma vez que pode ocorrer a carência inicial de $\mathrm{N}$, decorrente da imobilização causada pela decomposição microbiana dos resíduos da cultura antecessora. Assim, em alguns casos, a antecipação da adubação nitrogenada, em relação às recomendações convencionais ou, até mesmo em relação à semeadura da cultura, pode ser mais eficiente no aumento da produtividade das culturas graníferas anuais (Kluthcouski et al., 2006).
Testando métodos de adubação nitrogenada em plantio direto e avaliando a disponibilidade de N, Ros et al. (2003) verificaram que a aplicação total de $\mathrm{N}$ na semeadura ou em cobertura não diferiram na produtividade de grãos de trigo (Triticum aestivum). Hafez \& Kobata (2012), avaliando fontes de N em cultivares de trigo, concluíram que a aplicação de sulfato de amônio aumentou o número de espiguetas mais que a aplicação de ureia, o que foi determinante na produtividade de trigo sob irrigação. Entretanto, há necessidade de mais estudos com o uso do $\mathrm{N}$ para cultura do trigo em regiões com inverno seco e irrigação controlada.

$\mathrm{O}$ estudo de fontes de $\mathrm{N}$ também é fundamental, uma vez que esses fertilizantes apresentam diferenças quando aplicados ao solo, em especial quanto às perdas de N. A ureia é o fertilizante nitrogenado mais utilizado no mundo por causa das vantagens em termos de custo, facilidade de fabricação e despesa final para o agricultor (Cantarella, 2007). Entretanto, a ureia apresenta séria limitação quando aplicada na superfície do solo, em razão das chances de perdas por volatilização da amônia. Já o sulfato de amônio não volatiliza na forma de amônia quando o $\mathrm{pH}$ é inferior a 7, mas esse fertilizante tem sua eficiência reduzida por lixiviação de nitratos. Com o objetivo de aumentar a eficiência dos adubos nitrogenados, recentemente 
foi lançado no mercado o adubo nítrico amoniacal, sulfonitrato de amônio (Entec®), que possui $26 \%$ de $\mathrm{N}$ total (18,5\% na forma amoniacal e $7,5 \%$ na forma nítrica) e $12 \%$ de enxofre. O Entec ${ }^{\circledR}$ apresenta em sua composição moléculas de DMPP $(3,4$ dimetilpirazolfosfato) que atuam na inibição de nitrificação (Los Fertilizantes..., 2006). A inibição do processo de nitrificação é interessante, pois mantém o $\mathrm{N}$ na forma de amônio, forma mais facilmente assimilável pelas plantas, pois não precisa ser reduzida como o nitrato, e que apresenta menor mobilidade no solo, ficando, assim, mais tempo disponível para as plantas e reduzindo as perdas de $\mathrm{N}$ por lixiviação do nitrato.

A região do Cerrado brasileiro tem enorme potencial para a expansão da cultura do trigo com a perspectiva de propiciar, em médio prazo, a autossuficiência na produção nacional. Porém, para obtenção de altas produtividades de trigo são essenciais o manejo adequado da adubação nitrogenada e a utilização de cultivares de alto potencial produtivo. Contudo, os estudos sobre a resposta dos componentes de produção e produtividade do trigo à adubação nitrogenada são insuficientes e carecem de informações em condições específicas do ambiente dos cerrados, onde há necessidade do uso da irrigação. Sendo assim, objetivou-se avaliar doses e fontes de $\mathrm{N}$, sendo uma com inibidor de nitrificação (Entec $\left.{ }^{\circledR}\right)$, aplicada totalmente em semeadura ou em cobertura, nos componentes de produção e na produtividade de dois cultivares de trigo irrigado, em plantio direto.

\section{MATERIAL E MÉTODOS}

O experimento foi conduzido em 2008, em área experimental localizada em Selvíria, MS, com coordenadas geográficas de $51^{\circ} 22^{\prime} \mathrm{W}$ e $20^{\circ} 22^{\prime} \mathrm{S}$ e altitude de $335 \mathrm{~m}$. O solo foi classificado como Latossolo Vermelho distrófico, textura argilosa (Embrapa, 2013), que foi originalmente ocupado por vegetação de cerrado e cultivado por culturas anuais há mais de 25 anos. A classificação climática da região de acordo com Köppen é Aw, definida como tropical úmido com estação chuvosa no verão e seca no inverno. A temperatura média anual é de $23,5^{\circ} \mathrm{C}$, a precipitação pluvial média anual é de $1.370 \mathrm{~mm}$ e a umidade relativa do ar média anual entre 70 e $80 \%$. Os valores de precipitação pluvial $(\mathrm{mm})$, umidade relativa do ar (\%) e temperatura média $\left({ }^{\circ} \mathrm{C}\right)$ da área de cultivo durante a condução do experimento constam na figura 1.

As características químicas do solo da área experimental na camada de 0-0,20 m foram determinadas antes da instalação do experimento, segundo métodos propostos por Raij \& Quaggio (1983), e apresentaram os seguintes resultados: $32 \mathrm{mg} \mathrm{dm}^{-3}$ de $\mathrm{P}$ (resina); $22 \mathrm{mg} \mathrm{dm}^{-3}$ de $\mathrm{S} ; 29 \mathrm{~g} \mathrm{dm}^{-3}$ de matéria orgânica; 5,4 de $\mathrm{pH}\left(\mathrm{CaCl}_{2}\right)$; $\mathrm{K}, \mathrm{Ca}, \mathrm{Mg}, \mathrm{H}+\mathrm{Al}: 3,2$;
31,$0 ; 16,0$; e $29,0 \mathrm{mmol}_{\mathrm{c}} \mathrm{dm}^{-3}$, respectivamente; e $64 \%$ de saturação por bases. Com base nas características químicas do solo da área experimental, calculou-se a adubação química básica no sulco de semeadura, constante para todos os tratamentos, que foi de $20 \mathrm{~kg} \mathrm{ha}^{-1}$ de $\mathrm{N}$ (ureia), $70 \mathrm{~kg} \mathrm{ha}^{-1}$ de $\mathrm{P}_{2} \mathrm{O}_{5}$ (superfosfato simples) e $40 \mathrm{~kg} \mathrm{ha}^{-1} \mathrm{de}_{2} \mathrm{O}$ (cloreto de potássio). Essa adubação básica tem como objetivo promover condições para que as plantas de trigo tenham desenvolvimento inicial satisfatório e produzam matéria seca para análise nutricional e produtiva, principalmente aquelas que não receberam doses de N. A adubação nitrogenada de cobertura foi realizada nas entrelinhas das parcelas, sem incorporação ao solo, aos 40 dias após a emergência das plantas, quando essas estavam no estádio de emborrachamento da cultura; em seguida, efetuou-se a irrigação por aspersão (lâmina de $14 \mathrm{~mm}$ ). Essa operação é comum nos sistemas de produção de grãos irrigados, quando se aplica a ureia.

O delineamento estatístico foi de blocos ao acaso, em um esquema fatorial $5 \times 3 \times 2 \times 2$, com três repetições, combinando cinco doses de $\mathrm{N}(0,50,100$, 150 e $200 \mathrm{~kg} \mathrm{ha}^{-1}$ ), três fontes de N (Entec ${ }^{\circledR}$, sulfato de amônio e ureia) e duas épocas de aplicação de $\mathrm{N}$ (na semeadura, ao lado das linhas para evitar o efeito salino nas plântulas, ou em cobertura), em dois cultivares de trigo (Embrapa 21 e IAC 370). As dimensões das parcelas foram de $5 \mathrm{~m}$ de comprimento com cinco linhas espaçadas de $0,17 \mathrm{~m}$ e 80 sementes por metro. O cultivar de trigo Embrapa 21 é recomendado para região de cerrado e apresenta qualidade panificativa intermediária e resistência a todas as raças de ferrugem da folha e do colmo verificadas no Brasil (Andrade et al., 1998). Já o cultivar IAC 370 é indicado para áreas irrigadas e evidencia alto potencial produtivo, hábito vegetativo semiprostrado e resistência ao acamamento, porém necessita de solos sem camadas compactadas (Furlani et al., 2002).

Instalou-se o experimento em local onde o sistema plantio direto foi implantado há 9 anos. Essa área era anteriormente ocupada com a cultura do milho (Zea mays). A área foi dessecada, utilizando o herbicida glifosato (1.500 $\mathrm{g} \mathrm{ha}^{-1}$ do i.a.). Antes da semeadura, foi realizado o tratamento de sementes com carboxin + thiram $(60+60$ g i.a. para $100 \mathrm{~kg}$ de sementes $)$, para evitar o aparecimento de eventuais doenças causadas por patógenos de solo. A semeadura foi realizada mecanicamente, no dia 11 de junho de 2008. Em seguida, a área foi irrigada por aspersão, por meio de pivô central com uma lâmina de água de aproximadamente $14 \mathrm{~mm}$. As plântulas emergiram 5 dias após a semeadura.

Fez-se o manejo de plantas daninhas com a aplicação do herbicida metsulfuron methyl (3,0 $\mathrm{g} \mathrm{ha}^{-1}$ do i.a.), em pós-emergência. $\mathrm{O}$ fornecimento de água foi efetuado de três em três dias, ou quando necessário por aspersão por meio de um sistema fixo de irrigação 


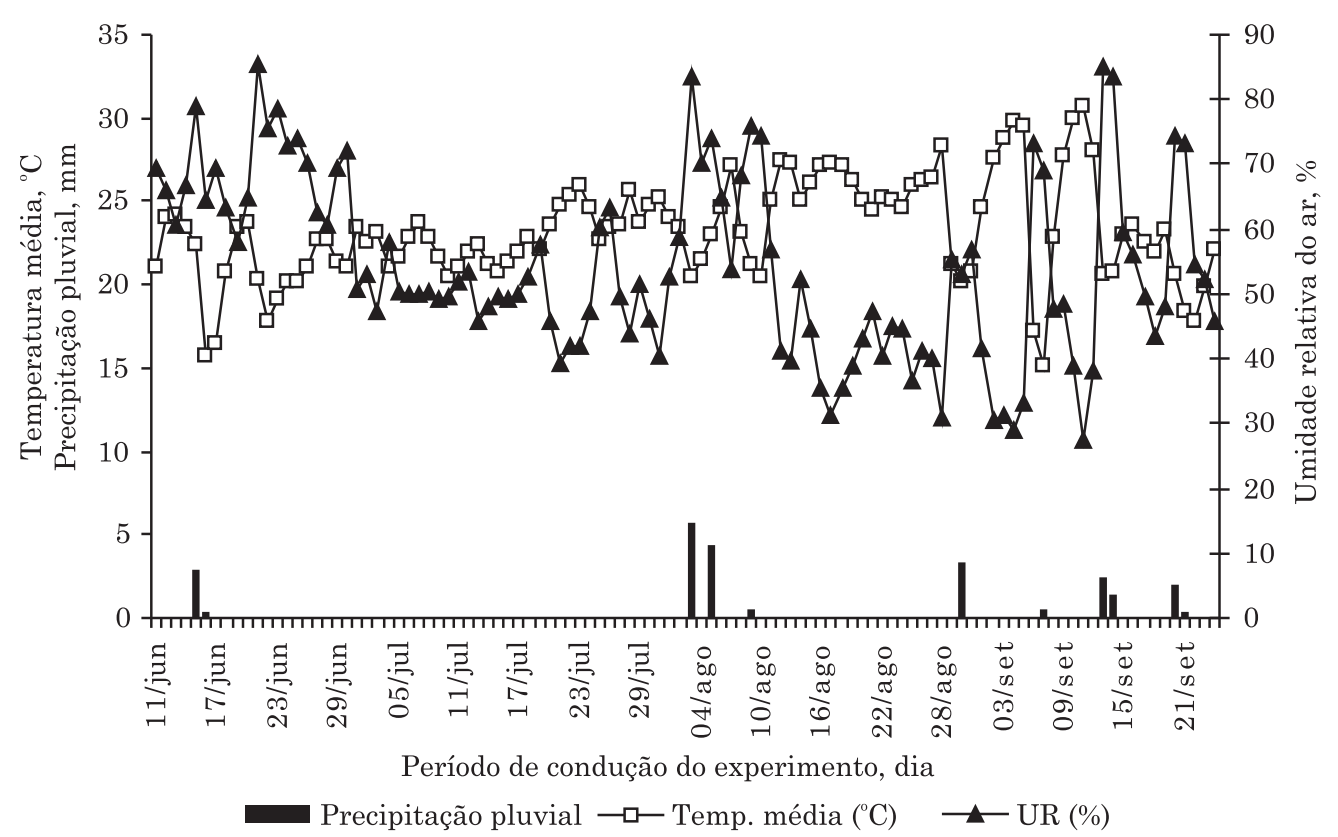

Figura 1. Precipitação pluvial, temperatura média e umidade relativa do ar, durante a condução do experimento.

do tipo pivô central. A concentração de $\mathrm{N}$ foliar foi determinada na folha bandeira, coletada no início do florescimento da cultura (Cantarella et al., 1997). Definiu-se a concentração de clorofila indiretamente por meio das leituras SPAD, com auxílio de um clorofilômetro digital em cinco plantas de trigo por parcela, na última folha recém-expandida madura. Foram avaliadas duas épocas: aos 38 dias após a emergência (DAE), antes da adubação nitrogenada de cobertura, e aos $68 \mathrm{DAE}$, quando as plantas estavam no estádio de florescimento.

Discriminou-se a altura de plantas na maturação, como sendo a distância do nível do solo até a extremidade das espigas, excluindo-se as aristas. Já o número de espigas por $\mathrm{m}^{2}$ foi determinado em três linhas por parcela, excluindo-se $0,5 \mathrm{~m}$ de bordadura nas extremidades. A colheita do trigo foi realizada manualmente e individualmente por unidade experimental aos 104 dias após a emergência das plantas, quando $90 \%$ das espigas apresentavam os grãos com coloração típica de maduros (maturação fisiológica). O material colhido foi submetido à secagem ao sol e posteriormente trilhado. A limpeza do material foi realizada manualmente.

Para definir o número total de grãos por espiga, foram avaliadas 10 espigas por unidade experimental. A massa hectolítrica, correspondente à massa de grãos ocupada em um volume de $100 \mathrm{~L}$, foi determinada com teor de água dos grãos corrigidos para $13 \%$ na base úmida. A massa de 100 grãos foi determinada em balança de precisão, com teor de água dos grãos corrigidos para $13 \%$ (base úmida). A produtividade de grãos foi medida pela coleta das plantas contidas nas três linhas centrais de cada parcela. Após a trilhagem mecânica, os grãos foram quantificados e os dados transformados em $\mathrm{kg} \mathrm{ha}^{-1}$ a $13 \%$ (base úmida).

Os resultados foram submetidos à análise de variância como um fatorial triplo para o efeito de cultivares e as fontes de $\mathrm{N}$ e de épocas de aplicação; compararam-se as médias pelo teste de Tukey a $5 \%$ e ajustaram-se as equações de regressão para o efeito das doses de N. Procederam-se às análises de correlação para concentração foliar de $\mathrm{N}$ versus de clorofila e para produtividade de grãos versus os componentes de produção. Foi utilizado o programa de análise estatística SISVAR (Ferreira, 2008).

\section{RESULTADOS E DISCUSSÃO}

Não houve interação significativa entre os fatores doses, fontes e épocas de aplicação de $\mathrm{N}$, em nenhuma das avaliações realizadas. Constatou-se que os cultivares de trigo apresentaram diferença significativa para concentração de $\mathrm{N}$ e concentração de clorofila aos $38 \mathrm{DAE}$, antes da adubação nitrogenada de cobertura; o cultivar IAC 370 apresentou maior concentração de clorofila aos 38 DAE, enquanto Embrapa 21 foi superior quanto à concentração de $\mathrm{N}$ foliar (Quadro 1). Entretanto, ressalta-se que as concentrações de $\mathrm{N}$ foliar ficaram acima da faixa adequada (20 a $34 \mathrm{~g} \mathrm{~kg}^{-1}$ de matéria seca) para ambos os cultivares, principalmente para o Embrapa 21 que apresentou elevada concentração de N, em relação ao descrito por Cantarella et al. (1997). As leituras do clorofilometro (SPAD) foram, 
Quadro 1. Médias e coeficientes de variação (CV) referentes à concentração de clorofila aos 38 e 68 dias após a emergência (DAE), teor foliar de $\mathrm{N}$ e altura de plantas de dois cultivares de trigo, sob diferentes fontes de N, épocas de aplicação de $\mathrm{N}$ e doses de $\mathrm{N}$

\begin{tabular}{|c|c|c|c|c|}
\hline & Clorofila aos 38 DAE & Clorofila aos 68 DAE & Teor foliar de $\mathrm{N}$ & Altura de plantas \\
\hline & & & $\mathrm{g} \mathrm{kg}^{-1}$ & $\mathrm{~cm}$ \\
\hline \multicolumn{5}{|l|}{ Cultivar } \\
\hline IAC 370 & $38,21 \mathrm{a}$ & $46,66 \mathrm{a}$ & $35,25 \mathrm{~b}$ & $71,60 \mathrm{a}$ \\
\hline Embrapa 21 & $36,16 \mathrm{~b}$ & $46,08 \mathrm{a}$ & $58,72 \mathrm{a}$ & $71,06 \mathrm{a}$ \\
\hline \multicolumn{5}{|l|}{ Fonte de $\mathrm{N}$} \\
\hline Entec ${ }^{\circledR}$ & $36,91 \mathrm{a}$ & $45,74 \mathrm{a}$ & $46,30 \mathrm{a}$ & $70,88 \mathrm{a}$ \\
\hline Sulfato de amônio & $37,22 \mathrm{a}$ & $45,82 \mathrm{a}$ & $46,35 \mathrm{a}$ & 71,35 a \\
\hline Ureia & $37,46 \mathrm{a}$ & $47,54 \mathrm{a}$ & $48,30 \mathrm{a}$ & $71,77 \mathrm{a}$ \\
\hline \multicolumn{5}{|l|}{ Época de aplicação } \\
\hline Semeadura & $39,50 \mathrm{a}$ & $45,50 \mathrm{~b}$ & $44,63 \mathrm{~b}$ & $72,10 \mathrm{a}$ \\
\hline Cobertura & $34,87 \mathrm{~b}$ & $47,24 \mathrm{a}$ & $49,33 \mathrm{a}$ & $70,57 \mathrm{~b}$ \\
\hline \multicolumn{5}{|l|}{ Dose de N $\left(\mathrm{kg} \mathrm{ha}^{-1}\right)$} \\
\hline 0 & $34,60^{(1)}$ & $42,36^{(2)}$ & $38,46^{(3)}$ & $66,36^{(4)}$ \\
\hline 50 & 36,17 & 45,46 & 45,54 & 69,75 \\
\hline 100 & 37,56 & 46,47 & 46,33 & 74,44 \\
\hline 150 & 38,96 & 49,03 & 52,67 & 72,58 \\
\hline 200 & 38,63 & 48,49 & 51,92 & 73,53 \\
\hline Média geral & 37,19 & 46,37 & 46,98 & 71,33 \\
\hline CV (\%) & 10,20 & 11,97 & 15,93 & 6,70 \\
\hline
\end{tabular}

Equações de regressão em função das doses de N. ${ }^{(1)} \hat{y}=35,0134+0,0217 \times\left(R^{2}=0,90\right) .{ }^{(2)} \hat{y}=43,2010+0,0317 \times\left(R^{2}=0,88\right) .{ }^{(3)}$ $\hat{y}=40,1750+0,0681 \times\left(R^{2}=0,88\right)$. (4) $\hat{y}=66,2650+0,097 x-0,00033 x^{2}\left(R^{2}=0,90\right)$. Médias seguidas de letra iguais, na coluna, dentro de cultivares, fontes e épocas de aplicação de N, não diferem entre si pelo teste de Tukey a $5 \%$.

em média, 37 e 46 para primeira (38 DAE) e segunda (68 DAE) leitura, respectivamente (Quadro 1). O valor médio de 42 unidades SPAD na folha bandeira de trigo, obtido por Follett et al. (1992), situou-se abaixo desse valor para leitura realizada na mesma época e acima da leitura medida nas folhas mais novas do trigo.

Para as fontes de N, não houve efeito significativo para a altura de plantas, concentração de clorofila aos 38 e 68 DAE e concentração de N foliar de plantas de trigo (Quadro 1). Megda et al. (2009) também não verificaram diferença entre essas mesmas fontes de $\mathrm{N}$ para a concentração de $\mathrm{N}$ do trigo irrigado no cerrado. Ainda, Yano et al. (2005) não encontraram diferença entre ureia, sulfato de amônio e nitrato de amônio para a altura de plantas de trigo.

Com relação à época de aplicação, o fornecimento de $\mathrm{N}$ totalmente na semeadura proporcionou maior concentração de clorofila aos 38 DAE e maior altura de plantas (Quadro 1). Esses resultados evidenciaram que a antecipação da adubação nitrogenada elevou a concentração de clorofila, o que pode ter incrementado a atividade fotossintética, promovendo aumento na estatura das plantas de trigo. Já a aplicação de $\mathrm{N}$ em cobertura proporcionou maiores concentrações de $\mathrm{N}$ foliar e de clorofila aos 68 DAE nas plantas de trigo. Isso ocorreu porque a aplicação do $\mathrm{N}$ em cobertura é realizada mais próxima ao florescimento da cultura, período esse da coleta das folhas bandeiras para análise da concentração de $\mathrm{N}$, em que foi realizada a segunda leitura com o clorofilômetro. Megda et al. (2009) também constataram que a aplicação de $\mathrm{N}$ em cobertura proporcionou maior concentração de $\mathrm{N}$ nas folhas de trigo, em relação à aplicação do $\mathrm{N}$ totalmente em semeadura.

As doses de $\mathrm{N}$ aumentaram linearmente as concentrações de $\mathrm{N}$ e de clorofila, tanto aos 38 como aos $68 \mathrm{DAE}$ (Quadro 1). Isso é atribuído, principalmente, ao fato de que 50 a $70 \%$ do $\mathrm{N}$ total da folha ser integrante de enzimas que estão associadas aos cloroplastos (Chapman \& Barreto, 1997). O aumento da concentração de $\mathrm{N}$ na folha bandeira do trigo, em razão do aumento das doses de N, também foi relatado por Teixeira Filho et al. (2008), porém a resposta foi quadrática e até a dose de $100 \mathrm{~kg} \mathrm{ha}^{-1}$ de N.

Salienta-se que a vantagem da medição da concentração de clorofila é a de que não há consumo de luxo para constituição da molécula de clorofila (Blackmer \& Schepers, 1995). A leitura pode ser realizada em poucos minutos, possibilitando rápido diagnóstico do estado nutricional da planta em relação ao N. Deve-se considerar também que o aparelho tem custos mínimos de manutenção (Piekielek \& Fox, 1992), não há necessidade de retirada de folhas e o agricultor pode realizar quantas medições desejar.

A altura de plantas foi influenciada de forma quadrática pelas doses de $\mathrm{N}$, com ponto de máximo 
sendo alcançado com a estimativa de aplicação de $148 \mathrm{~kg} \mathrm{ha}^{-1}$ de N (Quadro 1). Ressalta-se que no experimento não foi constatado acamamento de plantas, mesmo nas maiores doses de N. Teixeira Filho et al. (2008) também não observaram acamamento de plantas e efeito significativo da aplicação de doses de $\mathrm{N}$ em cobertura, em dois cultivares de trigo irrigados por aspersão, na região do cerrado. Entretanto, Zagonel et al. (2002), trabalhando com doses de $\mathrm{N}(0,45,90$ e 135 $\mathrm{kg} \mathrm{ha}^{-1}$ ) em cobertura e densidades de plantas de trigo com e sem regulador de crescimento, verificaram que com a elevação da dose de $\mathrm{N}$ ocorreu aumento da altura das plantas, no entanto, sem a ocorrência de acamamento, o que foi em razão, segundo os autores, do clima ameno e com poucos ventos.

Os cultivares de trigo diferiram em relação ao número de grãos por espiga, sendo o IAC 370 superior ao Embrapa 21 (Quadro 2). Contudo, nessa avaliação, não houve diferença significativa entre as fontes de $\mathrm{N}$ (Quadro 2). O N aplicado totalmente em semeadura proporcionou maior número de grãos por espiga de trigo, demonstrando, assim, que o fornecimento de doses de $\mathrm{N}$ mais elevadas na adubação de semeadura do trigo pode ser interessante. As doses de $\mathrm{N}$ também influenciaram esse componente da produção, ajustando-se a função quadrática com ponto de máximo alcançado com a estimativa de aplicação de $128 \mathrm{~kg} \mathrm{ha}^{-1}$ de N. Bredemeier \& Mundstock (2001) também verificaram aumento no número de espiguetas e no número de grãos por espiga, quando o $\mathrm{N}$ foi aplicado por ocasião da emissão da terceira folha. Entretanto, Pettinelli Neto et al. (2002), estudando cinco doses de $\mathrm{N}$ em seis cultivares de trigo, constataram que não houve efeito das doses de $\mathrm{N}$ no número de grãos por espiga. Teixeira Filho et al. (2008) também não verificaram efeito das doses de $\mathrm{N}$ (entre 0 e $150 \mathrm{~kg} \mathrm{ha}^{-1}$ ) aplicadas em cobertura no número de grãos por espiga, com duas populações e em dois cultivares de trigo irrigado na região de cerrado. Entretanto, Coelho et al. (1998) observaram incremento no número de grãos por espiga do cultivar de trigo Embrapa 22, proporcionado pelo aumento das doses de N. Isso evidencia o efeito conjunto de doses e épocas de aplicação de N, cultivar, clima e solo.

Para Sangoi et al. (2007), sob altas densidades de semeadura, o número de espigas por $\mathrm{m}^{2}$ é o componente de produção mais importante para o trigo. Os cultivares IAC 370 e Embrapa 21 apresentaram número de espigas por $\mathrm{m}^{2}$ semelhantes (Quadro 2). As fontes de $\mathrm{N}$ também não diferiram significativamente para essa avaliação. Megda et al. (2009) também não encontraram diferença entre as fontes de $\mathrm{N}$ (sulfonitrato de amônio, sulfato de amônio e ureia) para o número de espigas por $\mathrm{m}^{2}$ de trigo irrigado, mas a aplicação de $\mathrm{N}$ em cobertura promoveu maior número de espigas por $\mathrm{m}^{2}$.

Quadro 2. Médias e coeficientes de variação (CV) referentes ao número de grãos por espiga, número de espigas por $\mathrm{m}^{2}$, massa hectolítrica, massa de 100 grãos e produtividade de grãos de dois cultivares de trigo, sob diferentes fontes de $\mathrm{N}$, épocas de aplicação de $\mathrm{N}$ e doses de $\mathrm{N}$

\begin{tabular}{|c|c|c|c|c|c|}
\hline & $\begin{array}{c}\text { Número de grãos } \\
\text { por espiga }\end{array}$ & $\begin{array}{l}\text { Número de espigas } \\
\text { por } \mathbf{m}^{2}\end{array}$ & $\begin{array}{c}\text { Massa } \\
\text { hectolítrica }\end{array}$ & $\begin{array}{l}\text { Massa de } \\
100 \text { grãos }\end{array}$ & $\begin{array}{l}\text { Produtividade } \\
\text { de grãos }\end{array}$ \\
\hline & & & $\operatorname{kg} 100 \mathrm{~L}^{-1}$ & $\mathrm{~g}$ & $\mathrm{~kg} \mathrm{ha} \mathrm{h}^{-1}$ \\
\hline \multicolumn{6}{|l|}{ Cultivar } \\
\hline IAC 370 & $47 \mathrm{a}$ & $318 \mathrm{a}$ & $76,62 \mathrm{~b}$ & $3,60 \mathrm{~b}$ & $3.939 \mathrm{a}$ \\
\hline Embrapa 21 & $43 \mathrm{~b}$ & $328 \mathrm{a}$ & 77,88 a & $3,77 \mathrm{a}$ & $3.956 \mathrm{a}$ \\
\hline \multicolumn{6}{|l|}{ Fonte de $\mathrm{N}$} \\
\hline Entec ${ }^{\circledR}$ & $46 \mathrm{a}$ & 319 a & $77,18 \mathrm{a}$ & $3,67 \mathrm{a}$ & $3.847 \mathrm{a}$ \\
\hline Sulfato de amônio & $47 \mathrm{a}$ & $321 \mathrm{a}$ & $77,23 \mathrm{a}$ & $3,67 \mathrm{a}$ & $3.968 \mathrm{a}$ \\
\hline Ureia & $43 \mathrm{a}$ & 329 a & $77,33 \mathrm{a}$ & $3,70 \mathrm{a}$ & $4.027 \mathrm{a}$ \\
\hline \multicolumn{6}{|l|}{ Época de aplicação } \\
\hline Semeadura & $48 \mathrm{a}$ & $308 \mathrm{~b}$ & 77,15 a & $3,72 \mathrm{a}$ & $3.963 \mathrm{a}$ \\
\hline Cobertura & $42 \mathrm{~b}$ & $339 \mathrm{a}$ & 77,35 a & $3,64 \mathrm{~b}$ & $3.932 \mathrm{a}$ \\
\hline \multicolumn{6}{|l|}{ Dose de N $\left(\mathrm{kg} \mathrm{ha}^{-1}\right)$} \\
\hline 0 & $39^{(1)}$ & $281^{(2)}$ & 77,17 & 3,68 & 2.570 \\
\hline 50 & 48 & 306 & 77,21 & 3,72 & 3.977 \\
\hline 100 & 46 & 333 & 77,46 & 3,69 & 4.598 \\
\hline 150 & 47 & 357 & 77,20 & 3,69 & 4.436 \\
\hline 200 & 46 & 339 & 77,20 & 3,63 & 4.157 \\
\hline Média geral & 45 & 323,6 & 77,25 & 3,68 & 3.947 \\
\hline CV (\%) & 18 & 19,21 & 3,14 & 7,14 & 22,87 \\
\hline
\end{tabular}

Equações de regressão em função das doses de N. ${ }^{(1)} \hat{y}=40,4894+0,1253 x-0,00049 x^{2}\left(R^{2}=0,76\right) .{ }^{(2)} \hat{y}=277,8612+0,8319$ $\mathrm{x}-0,0025 \mathrm{x}^{2}\left(\mathrm{R}^{2}=0,94\right)$. Médias seguidas de letra iguais, na coluna, dentro de cultivares, fontes e épocas de aplicação de $\mathrm{N}$, não diferem entre si pelo teste de Tukey a $5 \%$. 
$\mathrm{O}$ incremento das doses de $\mathrm{N}$ influenciou positivamente e de forma quadrática o número de espigas por $\mathrm{m}^{2}$, com ponto de máximo sendo alcançado com a estimativa de aplicação de $128 \mathrm{~kg} \mathrm{ha}^{-1}$ de N. Zagonel et al. (2002) e Teixeira Filho et al. (2007) também verificaram efeito significativo do aumento das doses de $\mathrm{N}$ aplicadas em cobertura na forma de ureia e no número de espigas de trigo por metro. Já Hafez \& Kobata (2012) encontraram aumento no número de espiguetas quando as plantas receberam sulfato de amônio em relação à ureia. Embora a ureia seja o fertilizante nitrogenado mais popular, os resultados indicaram a superioridade do sulfato de amônio para cultura do trigo (Chien et al., 2011).

A massa hectolítrica do cultivar Embrapa 21 foi superior a do cultivar IAC 370 (Quadro 2). Para as fontes de N não houve diferença significativa para essa mesma avaliação. A aplicação do $\mathrm{N}$ totalmente na semeadura também não diferiu da aplicação em cobertura para massa hectolítrica. Entretanto, ressalta-se que as massas hectolítricas obtidas no experimento estão pouco abaixo das que classificam o trigo como tipo 1 (> $\left.78 \mathrm{~kg} 100 \mathrm{~L}^{-1}\right)$. As doses de N não influenciaram a massa hectolítrica do trigo. Teixeira Filho et al. (2008) também não constataram efeito significativo de doses de $\mathrm{N}$ em cobertura na forma de ureia, na massa hectolítrica de dois cultivares de trigo irrigados por aspersão, enquanto Trindade et al. (2006) encontraram valores de massa hectolítrica decrescentes, conforme se aumentava a dose de $\mathrm{N}$, como ureia de 0 a $200 \mathrm{~kg} \mathrm{ha}^{-1}$.

A massa de 100 grãos do cultivar Embrapa 21 foi superior a do IAC 370 (Quadro 2). Entretanto, as fontes de $\mathrm{N}$ não influenciaram tal componente da produção. A antecipação da adubação nitrogenada propiciou maior massa de 100 grãos que a aplicação tradicional de N em cobertura. Entretanto, Megda et al. (2009) não verificaram diferença entre a aplicação de $\mathrm{N}$ totalmente em semeadura e em cobertura, na dose de $70 \mathrm{~kg} \mathrm{ha}^{-1}$ de $\mathrm{N}$. As doses de $\mathrm{N}$ também não influenciaram a massa de 100 grãos (Quadro 2). As respostas da massa de 100 ou 1000 grãos à adubação nitrogenada são muito variáveis. Zagonel et al. (2002) também observaram que a adubação nitrogenada não influenciou a massa de 1000 grãos. Por sua vez, Coelho et al. (1998), trabalhando com doses entre 0 e 120 $\mathrm{kg} \mathrm{ha}{ }^{-1}$ de N, verificaram aumento na massa de 1000 grãos até 30 e $37 \mathrm{~kg} \mathrm{ha}^{-1}$ de N, nas duas safras avaliadas, respectivamente, com diminuição nesse componente com a utilização de doses superiores de N. Já Teixeira Filho et al. (2007) obtiveram aumento da massa de 100 grãos até $68 \mathrm{~kg} \mathrm{ha}^{-1} \mathrm{de} \mathrm{N}$, aplicados em cobertura na forma de ureia.

A produtividade de grãos dos cultivares de trigo IAC 370 e Embrapa 21 não diferiu significativamente (Quadro 2). Também não houve diferença significativa entre as fontes de $\mathrm{N}$ para a produtividade de grãos. Essa ausência de resposta às fontes de $\mathrm{N}$ provavelmente ocorreu em razão de logo após a aplicação dessas ter sido efetuada a irrigação no experimento, reduzindo assim as perdas por volatilização, principalmente da amônia proveniente da ureia, o que também foi relatado por Souza et al. (2011). As fontes de N também apresentaram comportamento semelhante por causa da baixa precipitação registrada no período de cultivo, já que o experimento foi conduzido na estação seca. Comparações entre diversos fertilizantes nitrogenados foram feitas por vários autores e, em geral, havendo condições satisfatórias de umidade do solo, não têm sido encontradas diferenças na eficiência dessas fontes, como na produtividade de grãos de trigo no Cerrado para as fontes de $\mathrm{N}$ sulfonitrato de amônio, sulfato de amônio e ureia (Megda et al., 2009), e entre a ureia e o Entec ${ }^{\circledR}$ no sistema plantio direto (Silva et al., 2008).

Quanto às épocas de aplicação de N, constatou-se que a aplicação na semeadura não diferiu da aplicação de $\mathrm{N}$ em cobertura para produtividade de grãos (Quadro 2). Isso provavelmente ocorreu porque o solo onde o experimento foi conduzido apresentava boa fertilidade e drenagem, é bastante argiloso, apresentando médio teor de matéria orgânica; além disso, o trigo foi cultivado num período de seca. Portanto, a prática da aplicação antecipada do nutriente foi eficaz. Ros et al. (2003), testando métodos de adubação nitrogenada em plantio direto e avaliando a disponibilidade de $\mathrm{N}$, também verificaram que a aplicação de $\mathrm{N}$ total na semeadura ou em cobertura não diferiram na produtividade de grãos de trigo. Silva et al. (2008) também não encontraram diferença significativa entre a aplicação de $\mathrm{N}$ totalmente na semeadura e a tradicional aplicação em cobertura para produtividade de grãos de trigo.

As doses de $\mathrm{N}$ influenciaram a produtividade de grãos dos cultivares de trigo IAC 370 e Embrapa 21 (Figura 2), se ajustando às funções quadráticas, com

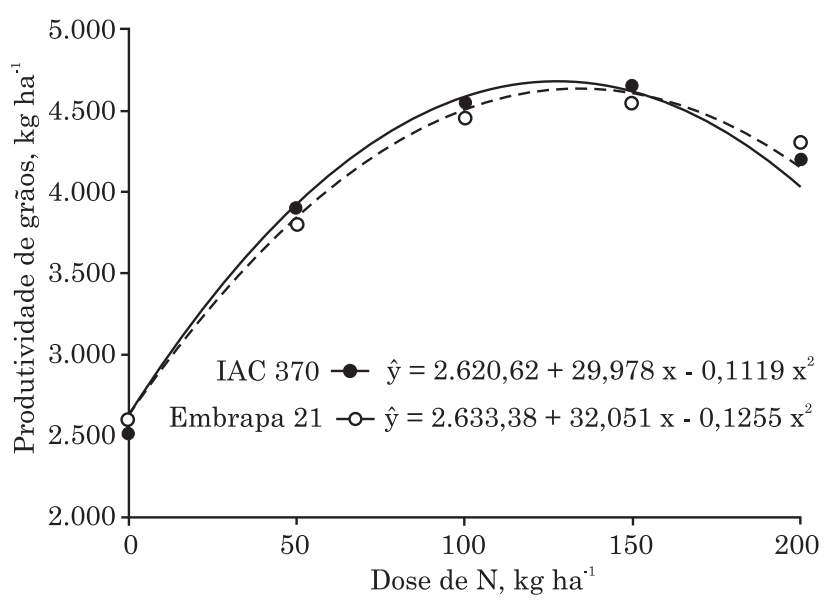

Figura 2. Produtividade de grãos de dois cultivares de trigo (IAC 370 e Embrapa 21), em resposta a diferentes doses de $\mathrm{N}$ aplicadas; médias de duas épocas de aplicação (na semeadura e em cobertura) e de três fontes de N (Entec ${ }^{\circledR}$, sulfato de amônio e ureia). Produção máxima de 134 e $128 \mathrm{~kg} \mathrm{ha}^{-1}$ para IAC 370 e Embrapa 21, respectivamente. 
a máxima produtividade alcançada nas doses estimadas de 134 e $128 \mathrm{~kg} \mathrm{ha}^{-1}$ de $\mathrm{N}$, respectivamente. Também Bredemeier \& Mundstock (2001), Zagonel et al. (2002), Trindade et al. (2006) e Teixeira Filho et al. $(2007 ; 2008)$ verificaram efeito do $\mathrm{N}$ na produtividade da cultura. No entanto, Pettinelli Neto et al. (2002) e Pottker et al. (1984) não verificaram efeito da aplicação de $\mathrm{N}$ na produtividade da cultura em razão do fornecimento de $\mathrm{N}$ pela cultura da soja cultivada há vários anos na área, e por causa das condições climáticas adversas (altas precipitações pluviais alternadas com períodos de seca), respectivamente. Isso evidencia que a eficiência do $\mathrm{N}$ aplicado depende das condições estudadas como cultivar, clima e manejo.

A produtividade de grãos do cultivar IAC 370 se correlacionou positivamente com as concentrações de clorofila aos $38 \mathrm{DAE}\left(\mathrm{r}=0,51^{* *}\right)$ e clorofila aos $68 \mathrm{DAE}$ $\left(\mathrm{r}=0,42^{*}\right)$, a concentração de $\mathrm{N}\left(\mathrm{r}=0,56^{* *}\right)$, a altura de plantas $\left(\mathrm{r}=0,68^{* *}\right)$, o número de grãos por espiga $\left(\mathrm{r}=0,45^{*}\right)$ e o número espigas por $\mathrm{m}^{2}\left(\mathrm{r}=0,62^{* *}\right)$. Já a produtividade de grãos do cultivar Embrapa 21 se correlacionou positivamente com a concentração de $\mathrm{N}\left(\mathrm{r}=0,45^{*}\right)$, a altura de plantas $\left(\mathrm{r}=0,70^{* *}\right)$ e o número espigas por $\mathrm{m}^{2}\left(\mathrm{r}=0,40^{*}\right)$. Piekielek \& Fox (1992) também constataram que a concentração de clorofila da folha se correlaciona positivamente com a produtividade das culturas.

Houve correlação positiva entre a concentração de $\mathrm{N}$ foliar e a concentração de clorofila aos $68 \mathrm{DAE}$ (leitura SPAD, no estádio de florescimento) dos cultivares de trigo IAC $370\left(\mathrm{r}=0,54^{* *}\right)$ e Embrapa 21 $\left(r=0,56^{* *}\right)$. Follett et al. (1992), estudando o uso do clorofilômetro para avaliar as doses de $\mathrm{N}$ da planta de trigo de sequeiro, também constataram associação positiva quando compararam as leituras da folha do clorofilômetro com a concentração foliar de N.

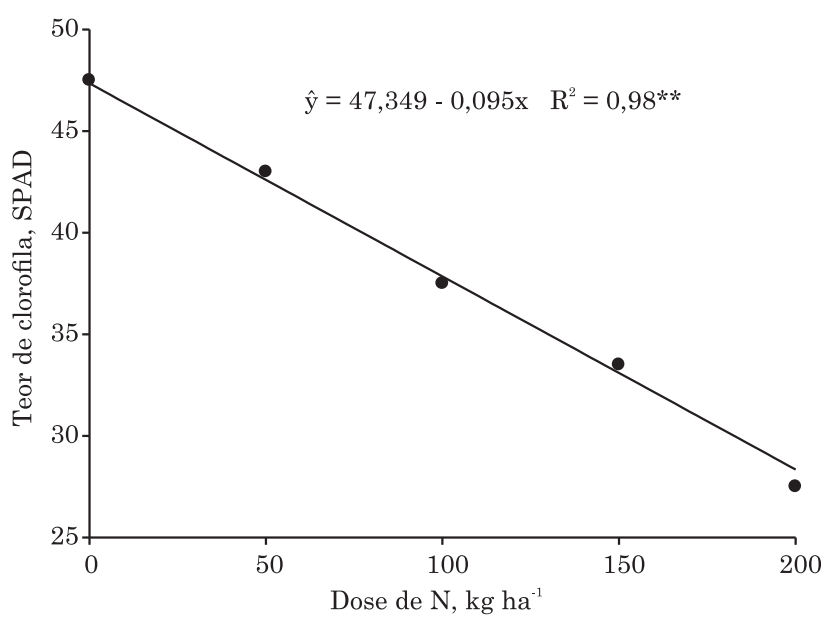

Figura 3. Doses de nitrogênio a serem aplicadas em cobertura a partir de leituras de clorofila (SPAD) das folhas de trigo, realizadas aos 38 dias após emergência.
Com base na avaliação das leituras SPAD do clorofilômetro, foi verificada a existência de uma relação do tipo $\mathrm{y}=\mathrm{b}+\mathrm{ax}$, sendo y o teor de clorofila aos 68 DAE e x a dose aplicada de N. A máxima produtividade de grãos foi obtida para $\mathrm{x}=131 \mathrm{~kg} \mathrm{ha}^{-1}$ de N, na média dos dois cultivares de trigo (Figura 2). Aplicando-se a máxima produtividade média de trigo na equação clorofila aos $68 \mathrm{DAE}=43,201+0,0317 \mathrm{x}$ (Quadro 1), obtém-se clorofila aos $68 \mathrm{DAE}=47,35$, sendo essa a leitura que proporcionaria a máxima produtividade de grãos. Salienta-se que as leituras SPAD continuaram aumentando com a aplicação das doses de N, mas a produtividade de grãos aumentou até a dose de $131 \mathrm{~kg} \mathrm{ha}^{-1}$. Face ao exposto, optou-se por avaliar a quantidade de $\mathrm{N}$ a ser aplicada em cobertura, considerando o incremento nas leituras SPAD até a aplicação de $131 \mathrm{~kg} \mathrm{ha}^{-1}$. Adicionalmente, a leitura SPAD da clorofila aos $38 \mathrm{DAE}$ avaliados nos tratamentos que não receberam $\mathrm{N}$ na semeadura foi 34,87 (Quadro 1). Então, a relação entre a dose a ser aplicada para se obter a máxima produtividade de grãos, denotada por $\mathrm{x}=131-\mathrm{x}_{\mathrm{a}}$, com relação a $\mathrm{y}$, tem a forma $\mathrm{y}=\mathrm{d}+\mathrm{c} \mathrm{x}$. Como descrito anteriormente, $\mathrm{y}=47,35$ para $\mathrm{x}_{\mathrm{a}}=131$ e $\operatorname{assim} \mathrm{x}=131-131=0$; sendo $d=47,349$. Portanto, para $_{\mathrm{a}}=0, \mathrm{x}=131-\mathrm{x}_{\mathrm{a}}=131$, obteve-se y $=34,87$, como explicado anteriormente. Então, de y $=\mathrm{d}+\mathrm{c}$ x com d $=47,349$, tem-se $34,87=47,349+\mathrm{c} 131 ; \operatorname{logo} \mathrm{c}=-0,095$. Por fim, obtém-se y $=47,349-0,095 \mathrm{x}$, em que $\mathrm{x}$ é a quantidade de $\mathrm{N}\left(\mathrm{kg} \mathrm{ha}^{-1}\right)$ a ser aplicada no momento da adubação nitrogenada de cobertura, buscando alcançar a máxima leitura no estádio de florescimento $(47,349)$, que proporcionaria a máxima produtividade de grãos; e y, a leitura SPAD, avaliada aos 38 dias após a emergência das plantas (Figura 3).

Isso evidencia a importância do nutriente tanto no que se refere ao estado nutricional da planta quanto à sua influência no perfilhamento da cultura, podendo proporcionar, assim, maior produtividade de grãos. Ressalta-se que as produtividades obtidas nessa região, tropical de baixa altitude, foram em média de $3947 \mathrm{~kg} \mathrm{ha}^{-1}$ (Quadro 2), mostrando que o trigo irrigado é possível alternativa na rotação de culturas de inverno no cerrado.

\section{CONCLUSÕES}

1. Os cultivares de trigo IAC 370 e Embrapa 21 apresentaram produtividades de grãos semelhantes.

2. As fontes nitrogenadas Entec ${ }^{\circledR}$, o sulfato de amônio e a ureia não diferiram quanto à produtividade de grãos de trigo e às demais avaliações.

3. $\mathrm{O} \mathrm{N}$ pode ser fornecido totalmente na semeadura ou em semeadura e cobertura para o cultivo do trigo irrigado sob plantio direto, nas condições edafoclimáticas dessa região de cerrado. 
4. A elevação das doses de $\mathrm{N}$ aumentou as concentrações foliares de $\mathrm{N}$ e de clorofila, a altura de plantas e o número de espigas por $\mathrm{m}^{2}$; e elevou a produtividade de grãos dos cultivares de trigo IAC 370 e Embrapa 21 até as doses de 134 e $128 \mathrm{~kg} \mathrm{ha}^{-1}$ de N, respectivamente, independentemente da época de aplicação e da fonte de $\mathrm{N}$.

5. A correlação positiva entre o teor de clorofila e a produtividade de grãos em razão das doses de $\mathrm{N}$ indicou que a adubação nitrogenada de cobertura pode ser recomendada a partir das leituras (SPAD) de clorofila foliar, realizadas aos 38 dias após emergência do trigo.

\section{LITERATURA CITADA}

ANDRADE, J.M.V.; ALBRECHT, J.C.; SOUSA, C.N.A.; BRAZ, A.J.B.P. \& SOUZA, M.A. Embrapa 21: Nova cultivar de trigo para Minas Gerais, Goiás, Mato Grosso e Distrito Federal. Pesq. Agropec. Bras., 33:1209-1213, 1998.

BLACKMER, T.M. \& SCHEPERS, J.S. Techniques for monitoring crop nitrogen status in corn. Commun. Soil Sci. Plant Anal., 25:1791-1800, 1995.

BREDEMEIER, C. \& MUNDSTOCK, C.M. Estádios fenológicos do trigo para a adubação nitrogenada em cobertura. R. Bras. Ci. Solo, 25:317-323, 2001.

CANTARELla, H.; RAIJ, B.van \& CAMARGO, C.E.O. Cereais. In: RAIJ, B.van; CANTARELLA, H.; QUAGGIO, J.A. \& FURLANI, A.M.C., eds. Recomendações de calagem e adubação para o Estado de São Paulo. Campinas, Instituto Agronomico de Campinas, 1997. 285p. (Boletim Técnico, 100)

CANTARELLA, H. Uso de inibidor da urease para aumentar a eficiência da uréia. In: YAMADA, T. \& ABDALLA, S.R.S., eds. Informações recentes para otimização da produção agrícola. Inf. Agron., 117: 1-21, 2007.

CHAPMAN, S.C. \& BARRETO, H.J. Using a chlorophyll meter to estimate specific leaf nitrogen of tropical maize during vegetative growth. Agron. J., 89:557-562, 1997.

CHIEN, S.H.; GEARHART, M.M. \& VILLAGARCIA, S. Comparison of ammonium sulfate with other nitrogen and sulfur fertilizers in increasing crop production and minimizing environmental impact: a review. Soil Sci., 176:327-335, 2011.

COELHO, M.A.O.; SOUZA, M.A.; SEDIYAMA, T.; RIBEIRO, A.C. \& SEDIYAMA, C.S. Resposta da produtividade de grãos e outras características agronômicas do trigo Embrapa-22 irrigado ao nitrogênio em cobertura. R. Bras. Ci. Solo, 22:555-561, 1998.

EMPRESA BRASILEIRA DE PESQUISA AGROPECUÁRIA EMBRAPA. Sistema brasileiro de classificação de solos. 3.ed. Brasília, Embrapa Tecnologia da Informação, 2013. $353 p$.

ERNANI, P.R. Disponibilidade de nitrogênio e adubação nitrogenada para macieira. Lages, Graphel, 2003. 76p.
FERREIRA, D.F. SISVAR: Um programa para análises e ensino de estatística. R. Symposium, 2:36-41, 2008.

FOLLETT, R.H.; FOLLETT, R.F. \& HALVORSON, A.D. Use of a chlorophyll meter to evaluate the nitrogen status of dryland winter wheat. Commun. Soil Sci. Plant Anal., 23:687-697, 1992.

FURLANI, A.M.C.; GUERREIRO FILHO, O.; COELHO, R.M.; BETTI, J.A. \& FREITAS, S.S. Recomendações da comissão técnica de trigo para 2002. 3.ed. Campinas, Instituto Agronômico de Campinas, 2002. 92p. (Série Tecnológica APTA, Boletim Técnico IAC, 167)

HAFEZ, E.E.D.M.M. \& KOBATA, T. The effect of different nitrogen sources from urea and ammonium sulfate on the spikelet number in egyptian spring wheat cultivars on well watered pot soils. Plant Produc. Sci., 15:332-338, 2012.

KLUTHCOUSKI, J.; AIDAR, H.; THUNG, M. \& OLIVEIRA, F.R.A. Manejo antecipado do nitrogênio nas principais culturas anuais. Inf. Agron., 113:1-24, 2006.

LOS FERTILIZANTES y su uso. 4.ed. Roma, FAO/IFA, 2002. p.87. Disponível em: <www.fertilizer.org>. Acesso em: 05 set. 2006 .

MEGDA, M.M.; BUZETTI, S.; ANDREOTTI, M.; TEIXEIRA FILHO, M.C.M. \& VIEIRA, M.X. Resposta de cultivares de trigo ao nitrogênio em relação às fontes e épocas de aplicação sob plantio direto e irrigação por aspersão. Ci. Agrotec, 33:1055-1060, 2009.

PIEKIELEK, W.P. \& FOX, R.H. Use of a chlorophyll meter to predict sidedress nitrogen requirements for maize. Agron. J., 84:59-65, 1992.

PETTINELLI NETO, A.; CRUSCIOL, A.C.; BICUDO, S.J.; FREITAS, J.G. \& PULZ, A.L. Eficiência e resposta de genótipos de trigo irrigado ao nitrogênio para o Estado de São Paulo. In: CONGRESSO DE INICIAÇÃO CIENTIFICA, 14., Presidente Prudente, 2002. Anais... Presidente Prudente, UNESP-Programa de Iniciação Científica da UNESP, 2002. CD-ROM

POTTKER, D.; FABRÍCIO, A.C. \& NAKAYAMA, L.H.I. Doses e métodos de aplicação de nitrogênio para a cultura do trigo. Pesq. Agropec. Bras., 19:1197-1201, 1984.

RAIJ, B.van \& QUAGGIO, J.A. Métodos de análise de solo para fins de fertilidade. Campinas, Instituto Agronômico de Campinas, 1983. p.11-31. (Boletim Técnico, 81)

ROS, C.O.; SALET R.L.; PORN, R.L. \& MACHADO, J.N.C. Disponibilidade de nitrogênio e produtividade de milho e trigo com diferentes métodos de adubação nitrogenada no sistema plantio direto. Ci. Rural, 33:799-804, 2003.

SANGOI, L.; BERNS, A.C.; ALMEIDA, M.L.; ZANIN, C.G. \& SCHWEITZER, C. Características agronômicas de cultivares de trigo em resposta à época da adubação nitrogenada de cobertura. Ci. Rural, 37:1564-1570, 2007.

SILVA, S.A.; ARF, O.; BUZETTI, S. \& SILVA, M.G. Fontes e épocas de aplicação de nitrogênio em trigo em sistema plantio direto no cerrado. R. Bras. Ci. Solo, 32:2717-2722, 2008. 
SOUZA, J.A.; BUZETTI, S.; TEIXEIRA FILHO, M.C.M.; ANDREOTTI, M.; SÁ, M.E. \& ARF, O. Adubação nitrogenada na cultura do milho safrinha irrigado em plantio direto. Bragantia, 70:447-454, 2011.

TEIXEIRA FILHO, M.C.M.; BUZETTI, S.; ALVAREZ, R.C.F.; FREITAS, J.G.; ARF, O. \& SÁ, M.E. Resposta de cultivares de trigo irrigado por aspersão ao nitrogênio em cobertura na região do Cerrado. Acta Sci. Agron., 29:421-425, 2007.

TEIXEIRA FILHO, M.C.M.; BUZETTI, S.; ALVAREZ, R.C.F.; FREITAS, J.G.; ARF, O. \& SÁ, M.E. Desempenho agronômico de cultivares de trigo em resposta a população de plantas e a adubação nitrogenada. Científica, 36:97-106, 2008.
TRINDADE, M.G.; STONE, L.F.; HEINEMANN, A.B.; CÁNOVAS, A.D. \& MOREIRA, J.A.A. Nitrogênio e água como fatores de produtividade do trigo no cerrado. R. Bras. Eng. Agric. Amb., 10:24-29, 2006.

YANO, G.T.; TAKAHASHI, H.W. \& WATANABE. S.T. Avaliação de fontes de nitrogênio e épocas de aplicação em cobertura para o cultivo do trigo. Semina, 26:141-148, 2005.

ZAGONEL, J.; VENÂNCIO, W.S.; KUNZ, R.P. \& TANAMATI, H. Doses de nitrogênio e densidade de plantas com e sem um regulador de crescimento afetando o trigo, cultivar OR-1. Ci. Rural, 32:25-29, 2002. 